\title{
The climate regime shift over the Pacific during 1996/1997
}

\author{
Chi-Cherng Hong $\cdot$ Yi-Kai Wu $\cdot$ Tim Li $\cdot$ \\ Chih-Chun Chang
}

Received: 16 March 2013 / Accepted: 2 July 2013/Published online: 17 July 2013

(c) The Author(s) 2013. This article is published with open access at Springerlink.com

\begin{abstract}
A climate regime shift (CRS) in the Pacific sea surface temperature (SST) pattern was identified in 1996/1997. This decadal SST change is characterized by a warming over the equatorial western Pacific (EWP) and mid-latitude North and South Pacific and a cooling in the equatorial central Pacific (ECP). The large-scale atmospheric circulation change associated with this CRS exhibits a pair of low-level anticyclonic (cyclonic) gyres off the EWP (ECP) and a zonal-vertical overturning circulation anomaly along the equator. Both the empirical orthogonal function and singular vector decomposition analyses indicate that the CRS signal in 1996/1997 is robust. A mixed layer heat budget analysis suggests that the abrupt change of SST in the EWP and ECP is attributed to different physical processes. The abrupt warming over the EWP was initiated by a short wave radiation (SWR) anomaly in association with a preceding warming in the ECP. The cooling in the ECP happened about 6 months later than that of the EWP and was primarily attributed to anomalous oceanic zonal and vertical temperature advections.
\end{abstract}

Keywords Climate regime shift - Mixed layer heat budget . Short wave radiation - Oceanic temperature advections

C.-C. Hong $(\varangle) \cdot$ Y.-K. Wu · C.-C. Chang

Department of Earth and Life, Taipei Municipal University of Education, 1 Ai Kuo West Road, Taipei 10048, Taiwan e-mail: cchong@tmue.edu.tw; hong0202@gmail.com

T. $\mathrm{Li}$

IPRC/SOEST, University of Hawaii at Manoa, Honolulu, Hawaii

\section{Introduction}

The natural variability of sea surface temperature (SST) over the Pacific basin involves multiple time scales, and affects the atmospheric circulation in local and remote regions. For example, a negative SST anomaly (SSTA) in the western North Pacific (WNP), persisting for a few months following an El Niño mature winter, plays a crucial role in bridging the Pacific-East Asia teleconnection (e.g., Wang et al. 2000; Li et al. 2006; Wu et al. 2009, 2010). The flip-flop back and forth of positive and negative SST anomalies in the tropical Indian Ocean (IO) tightly links to the tropospheric biennial oscillation (TBO, Meehl 1993; Chang and $\mathrm{Li}$ 2000). On the interdecadal timescale, it was well known that the Pacific basin SST experienced a great climate regime shift (CRS) around 1976/1977 (Miller et al. 1994; Wang 1995), with a pronounced warming in the tropics and a cooling over the mid-latitudes. This CRS led to a significant circulation change over various regions of the globe, including East Asia (Chang et al. 2000a, b; Hung et al. 2004; Zhang et al. 2004; Kwon et al. 2005; Zhou et al. 2009; Li et al. 2010).

Recent studies (e.g., McPhaden et al. 2011) suggested that the equatorial Pacific underwent another regime shift around 1998/1999. It is argued that this CRS is the cause of El Niño behavior change from a dominant eastern Pacific warming type to a dominant central Pacific (CP) warming type (Chung and Li 2012; Xiang et al. 2012). However, such a climate regime shift was confined in the equatorial region. For the interdecadal timescale, it is necessary to detect the regime shift signal in the global or at least basin scale.

In this study, we identify a new CRS in the Pacific basin, based on the analysis of two global-scale SST datasets. The new CRS occurred around 1996/1997. The rest of the paper 
is organized as following. In Sect. 2 we describe the data used in the current analysis. In Sect. 3 we present major results including the change of large scale atmospheric and oceanic circulation patterns associated with this CRS and physical processes responsible for the interdecadal change. Finally a conclusion and discussion are given in Sect. 4.

\section{Data and methodology}

The observational data used in this study includes (1) monthly atmospheric datasets of NCEP/NCAR Reanalysis I (Kalnay et al. 1996), (2) two global monthly SST datasets from the Met Office Hadley Center (HadSST1, Rayner et al. 2003) and the NOAA Extended Reconstructed SST V3 (NOAA-ERSST-V3, Smith et al. 2008), (3) NOAA outgoing long-wave radiation (OLR, Liebmann and Smith 1996), (4) global ocean heat flux OAFlux product (Yu et al. 2008), and (5) SODA 2.0.2 ocean data assimilation product (Carton et al. 2005).

A regime shift index (RSI, Rodionov 2004) is used to detect specific time for climate regime shift. An 8-year lowpass filter is adopted to isolate the interdecadal variability signal, following previous studies (e.g., Meehl et al. 1998).

\section{Results}

\subsection{Basin-scale climate regime shift in 1996-1997}

Figure 1 shows two dominant EOF patterns of 8-year lowpass-filtered SST over the Pacific for the period of 1958-2010 and their principle component (PC) time series. The first EOF mode contributes to $34-35 \%$ of the total variance, and resembles the structure of the Pacific Decadal Oscillation (PDO). The PC1 time series exhibits a significant abrupt shift in 1976/1977 in both the Hadley Center and NOAA SST datasets, as expected. The second EOF mode contributes to 24-29\% of the total variance, and its structure is similar to a $\mathrm{CP}$ cooling (or warming) pattern (Ashok et al. 2007). It is characterized by a marked warming over the northern and southern subtropics and western equatorial Pacific/Maritime Continent and a cooling in the equatorial CP. In contrast to the PC1, the PC2 shows a significant CRS around 1996/1997. Note that the amplitude of PC2 is greatly enhanced and larger than PC1 after $1996 / 1997$. If the whole period is separated into two periods (with a separation point in 1996/1997), the PC1(PC2) contributes $24 \%(10 \%)$ to the total variance in the earlier period (1950-1995), and the PC1(PC2) contributes $10 \%(14 \%)$ to the total variance in the latter period (1996-2010). Thus the calculation suggests that the PC1 dominates the SST variation in the period of
1950-1996, but the PC2 plays more a important role in contributing to the fluctuation of SST after 1997.

The statistical significance of EOF analysis could be tested by North role (1982), however, the number of degrees of freedom in geophysical time series is difficult to estimate reliably (Thiébaux and Zwiers 1984). Here, the Monte Carlo test based on the temporal subsampling of the series is used to examine the statistical significance test of EOF analysis. We computed the EOF 50 times with series made up of a half sample size, randomly selected from the total record. The error bars (1 SD of the eigenvalue) of the first 12 EOFs were plotted in Fig. 2. Whereas the error of the second mode is larger than that in the leading mode (i.e., the EOF1 is more stable than EOF2), the first three leading models are clearly separated. That indicates the first three EOFs are significant.

To further investigate the temporal evolution of the CRS related SSTA during the transition period, the temperature tendencies averaged over the boxes shown in Fig. 1b (where local SSTA maxima were located) were analyzed. It is noted that the CRS related warming in EWP was initiated around early 1992, the cooling in the ECP around middle 1993, and the warming in the northern subtropical Pacific after 1994 (Fig. 3). The result suggests that the CRS was originated from the tropics and extended to the extratropics; within the tropics, the CRS was firstly initiated in the EWP, followed by a cooling in the ECP.

The timing of the CRS is determined based on the RSI. The consistence of the CRS timing among the different SST datasets indicates that the detected regime shift signal is robust. To remove the effect of the global warming trend, the RSI was further calculated with the long-term SST linear trend removed. It turns out that the so-calculated RSI in the PC1 does not have a significant change (Fig. 4). We note that the liner-detrending might be not sufficient to remove the global warming effect, the other method proposed by Ting's et al. (2009) was used to remove the global warming effect and compare the analysis result with those derived from the linear-detrending method. It is noted that the first two eigenvalues and eigenvectors derived from these two methods resemble each other (not shown). Moreover, both PC2s exhibit the same CRS in 1996/1997 (Fig. 4). Therefore, detecting basin-scale low frequency SST variability may not be sensitive to the detrending method used.

\subsection{Circulation change associated with regime shift in $1996 / 1997$}

Figure 5 shows the interdecadal mean state difference of SST and atmospheric and oceanic circulation fields between the two periods, ID1 (1986-1996) and ID2 (1997-2007), in association with the CRS in 1996/1997. Similar to the EOF2 pattern, a La-Niña like SSTA, 

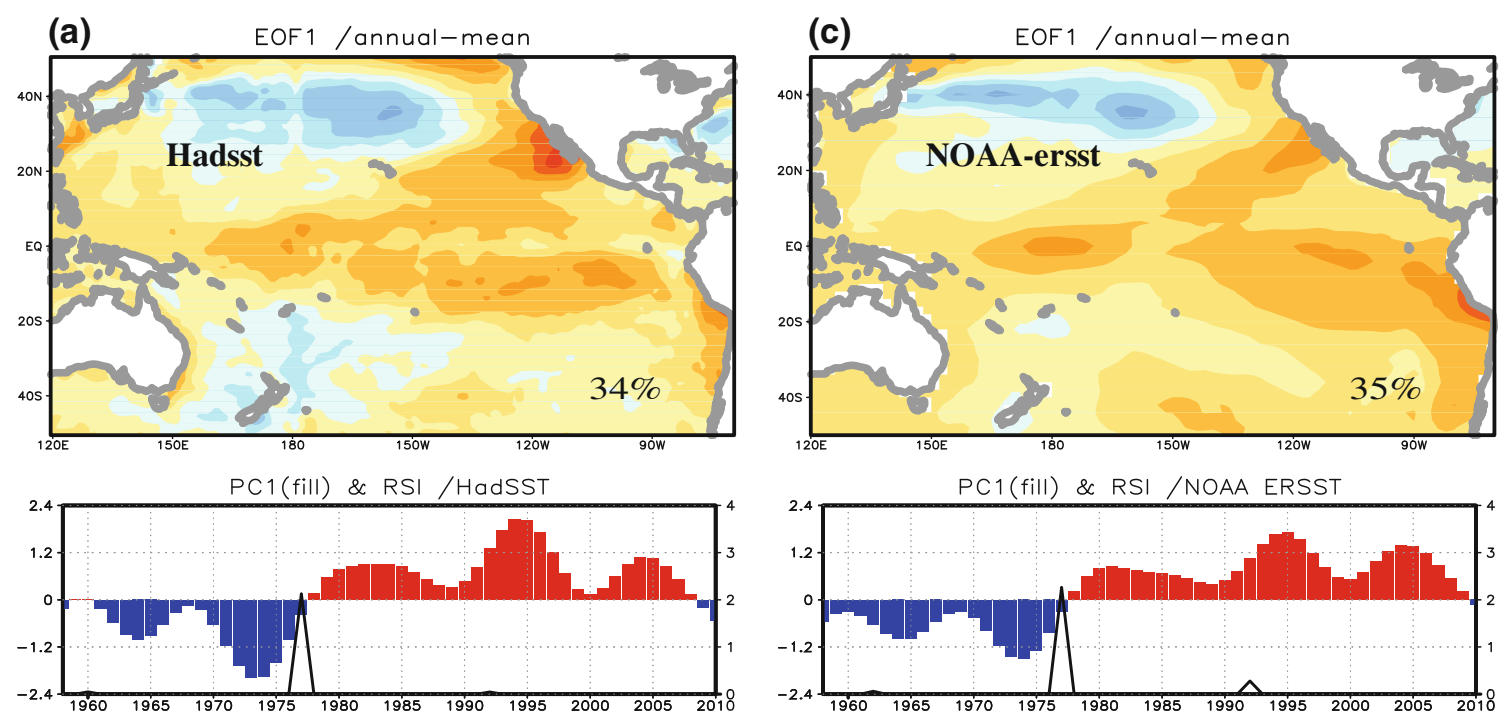

(b)
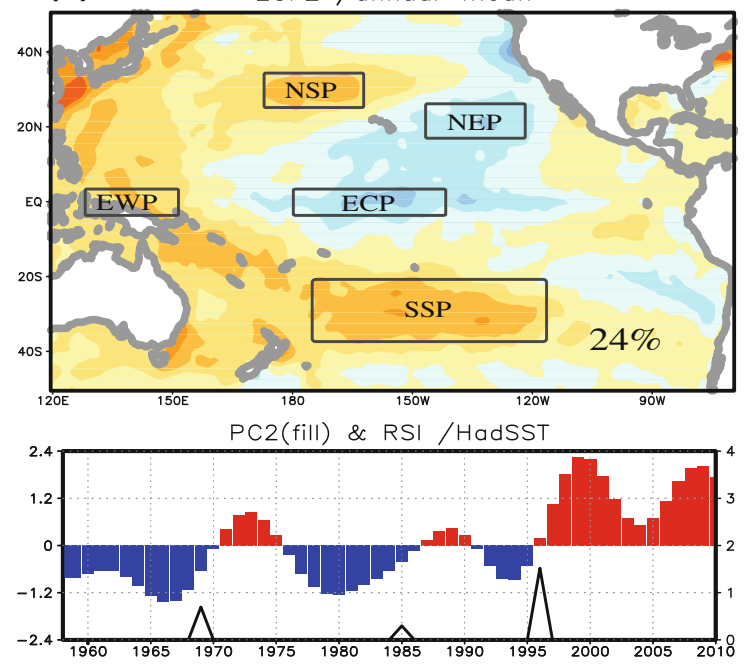

(d)
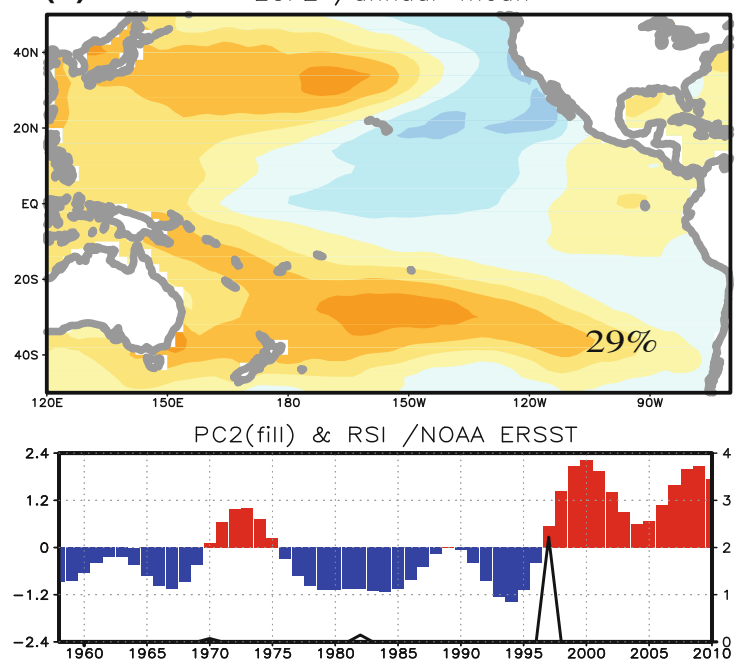

Fig. 1 The EOF patterns of 8-year low-pass-filtered SST and associated principle components (line filled) for (left) HadSST and (right) NOAA-ERSST. The first EOF model is shown in the upper

accompanied with a Matsuno-Gill-type (Matsuno 1966; Gill 1980) atmospheric circulation response, appears in the equatorial Pacific (Fig. 5a). The SST difference pattern shows a clear cooling in the ECP and strong warmings in the EWP and mid-latitude North and South Pacific. The decadal SST change pattern resembles that derived by Bond et al. (2003) and Peterson and Schwing (2003). The cooling in ECP leads the cooling in the northeast Pacific around 1 year (Fig. 3), suggesting the local CRS in the northeast Pacific is a part of the basin-scale CRS.

The rainfall change pattern in the tropics exhibits an east-west tri-pole structure (Fig. 5b), with a rainfall surplus in the maritime continent, the western Pacific (WP) and the eastern Pacific, and rainfall deficits in the CP. This tri-pole panel, and the second EOF mode is shown in the bottom panel. The black lines show the calculated regime shift index (RSI Rodionov 2004)

rainfall pattern was accompanied with anomalous zonalvertical overturning circulation at the equator, with anomalous ascending motion in the mid-troposphere over the maritime continent, WP, and EP, and anomalous descending motion over the $\mathrm{CP}$ (Fig. 5c). In addition to the east-west overturning circulation, there is local anomalous Hadley circulation over the maritime continent longitudes (not shown). Accompanied with this local Hadley circulation is anomalous descent over the off-equatorial WP, which helps strengthen the local warming through enhanced downward surface shortwave radiation.

Under the ocean surface, the subsurface $(\sim 100 \mathrm{~m})$ temperature difference between ID2 and ID1 shows an east-west dipole structure along the equatorial Pacific 


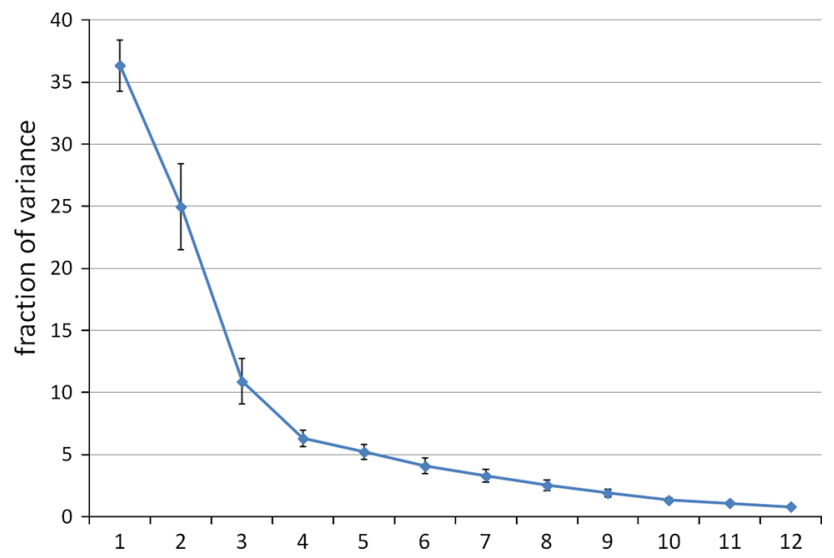

Fig. 2 The percentage variance (y-axis) of the first twelve eigenvalues. Monte Carlo test is used to estimate the error bar (one SD) of the eigenvalues. We computed the EOF 50 times with series made up of a half sample size, randomly selected from the total record

(Fig. 4d). This dipole-like temperature anomaly is accompanied with anomalous easterly wind stress and enhanced upwelling over the CP. The strengthened east-west tilting of the equatorial thermocline favors the development of a cold SSTA in the central and eastern equatorial Pacific.

The EOF analysis of 8-year low-pass-filtered $850 \mathrm{hPa}$ streamfunction shows the same CRS characteristics, with the PC1 changing point occurring in 1976/1977 and the PC2 changing point occurring in 1996/1997 (Fig. 6). This points out that the CRS signals in both 1976/1977 and 1996/1997 are robust, regardless of use of different atmospheric or oceanic data or analysis methods. The leading EOF mode of the streamfunction field shows an equatorially symmetric pattern, implying that two largescale atmospheric cyclonic gyres reside at both sides of the equators and atmospheric westerly anomalies at the equator. The spatial pattern of the EOF2 mode shows an eastwest contrast. While two atmospheric anticyclonic gyres appear in the WP, two atmospheric cyclonic gyres appear

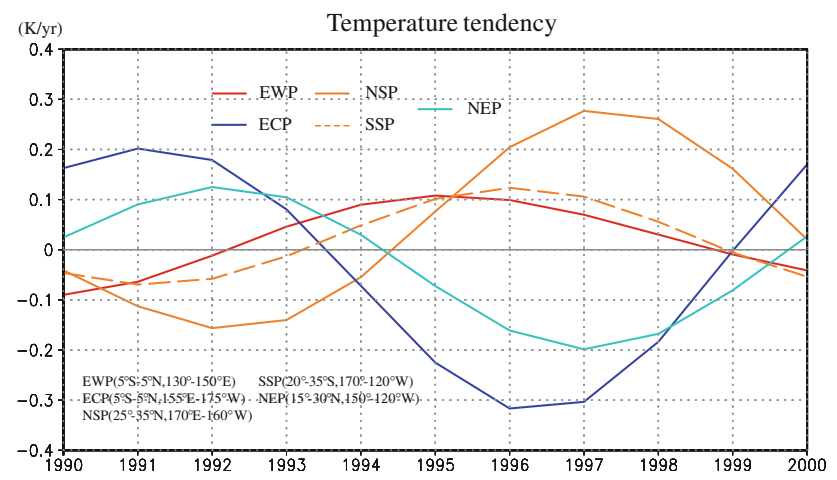

Fig. 3 Time series of the SST tendencies averaged over the boxes shown in Fig. 1b during the transition period around 1996/1997. An 8-year low-pass-filter was used in calculating the temperature tendencies

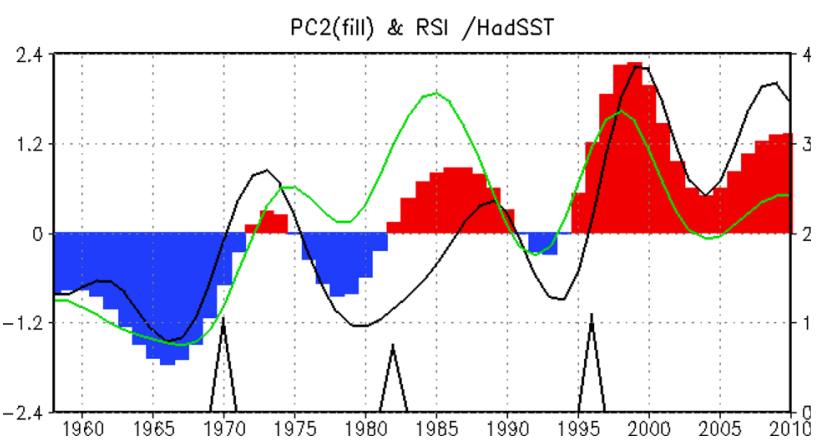

Fig. 4 Same as in Fig. 1c except for PC2 of 8-year low-pass filtered annual mean SSTA field with use of the linear-detrending method (shading) and the method developed by Ting et al. (2009) (green line). The black line indicates the PC2 of non-detrended data

in the eastern part of the basin. To the first order of approximation, the zonally asymmetric gyre pattern in EOF2 may be viewed as a Matsuno-Gill-type response to the equatorial SSTA pattern illustrated in Fig. 1b, d.

To further support this argument, we conducted a singular vector decomposition (SVD) analysis by pairing up the SST and $850 \mathrm{hPa}$ streamfunction fields (e.g., Bretherton et al. 1992). The heterogeneous correlation patterns for the first two leading SVD modes show that: the SST fields correlating against the time series of the leading SVD mode of the $850 \mathrm{hPa}$ stream function resembles the PDO, which is accompanied with a pair of basin-scale low-level cyclonic circulation in the Pacific (Fig. 7a, b); the SST fields correlating against the time series of the second SVD mode of the $850 \mathrm{hPa}$ stream function shows a triples structure in the equatorial Pacific, which are accompanied with a pair cyclonic and anti-cyclonic circulation anomalies in the equatorial eastern Pacific and western Pacific respectively (Fig. 7d, e). While the first SVD mode contributes to $65 \%$ of total squared covariance fraction, the second SVD mode contributes to $27 \%$. The correlation between the time series of the SST and $850-\mathrm{hPa}$ stream function of the leading (second) modes is 0.9 (0.93) (Fig. 7c, f), indicating the atmospheric gyre circulation illustrated in Fig. 6 is dynamically linked to the interdecadal SST patterns (shown in Fig. 1). Note that the correlation of the second SVD mode is larger than the leading SVD mode, suggesting the second SVD mode of the SST is strongly coupled with the $850-\mathrm{hPa}$ stream function. The SVD analysis confirms two significant CRS change points, with one occurred in 1976/1977 and the other occurred in 1996/1997 (Fig. 7c, f).

\subsection{Physical processes associated with the CRS} in $1996 / 1997$

To understand the cause of the SST regime shift in 1996/ 1997, we diagnose a mixed heat layer heat budget over the 
(a)

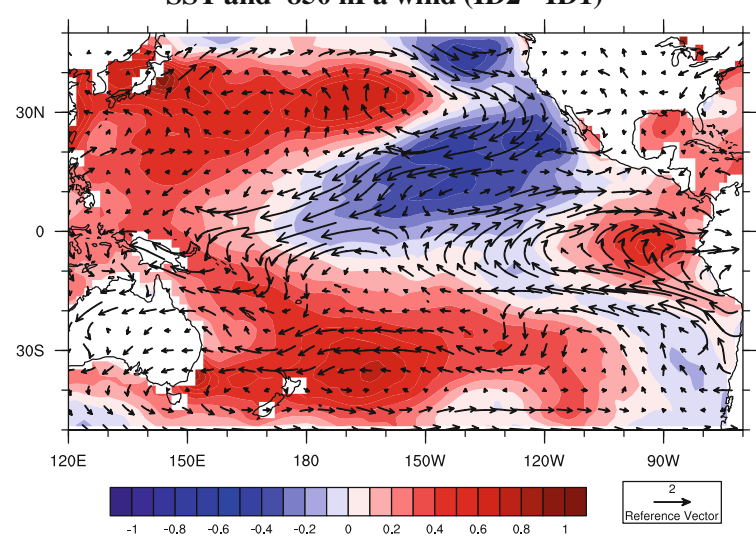

(b)

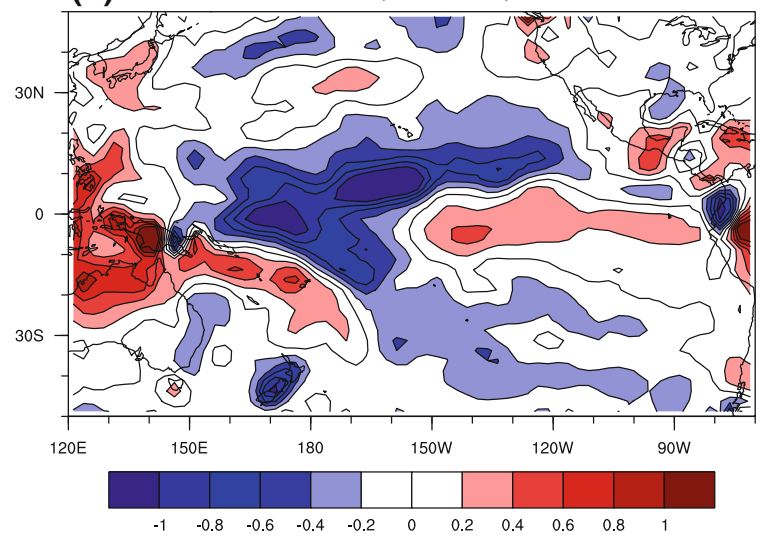

Fig. 5 The mean state difference (ID2 minus ID1) between 1986-1996 (ID1) and 1997-2007 (ID2) in association with the CRS in 1996/1997. a SST and $850 \mathrm{hPa}$ wind anomalies, b rainfall anomaly, $\mathbf{c}$ anomalous vertical overturning circulation averaged over

region of interests. Following Li et al. (2002), the mixed layer temperature tendency equation may be written as:

$$
\begin{aligned}
& \frac{\partial T^{\prime}}{\partial t}=-\left(V^{\prime} \cdot \nabla \bar{T}+\bar{V} \cdot \nabla T^{\prime}+V^{\prime} \cdot \nabla T^{\prime}\right) \\
& +\frac{1}{\rho C_{P} H}\left(Q_{S W}+Q_{L W}+Q_{L H}+Q_{S H}\right)^{\prime}+R
\end{aligned}
$$

where $T$ denotes the mixed layer temperature, $V=$ $(u, v, w)$ represents three dimensional mixed-layer ocean current, which is defined as the vertical average of currents from the surface to the bottom of the mixed layer, $\nabla=(\partial / \partial x, \partial / \partial y, \partial / \partial z)$ denotes 3 dimensional (3D) gradient operator, ()$^{\prime}$ represents the anomaly variables, $\left(^{-}\right)$the climatologic mean variables, term $-\left(V^{\prime} \cdot \nabla \bar{T}+\bar{V} \cdot \nabla T^{\prime}+\right.$ $\left.V^{\prime} \cdot \nabla T^{\prime}\right)$ is the summation of 3D temperature advection terms, $Q_{S W}, Q_{L W}, Q_{L H}$, and $Q_{S H}$ represent the net downward shortwave radiation at the ocean surface, net upward surface long-wave radiation, surface latent and sensible heat fluxes, $R$ represents the residual term, $\rho(=$ $\left.10^{3} \mathrm{~kg} / \mathrm{m}^{3}\right)$ is the density of water, $C_{P}\left(=4,000 \mathrm{JkgK}^{-1}\right)$ is (c)

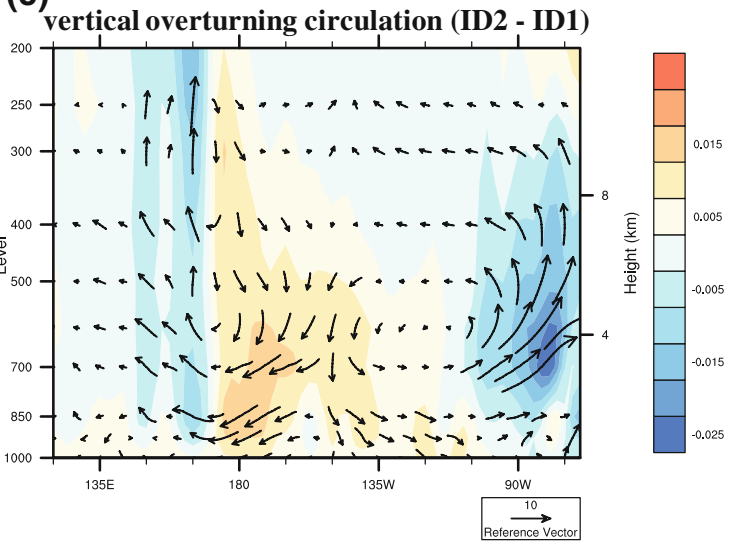

(d) ocean temp. and current (ID2 - ID1)

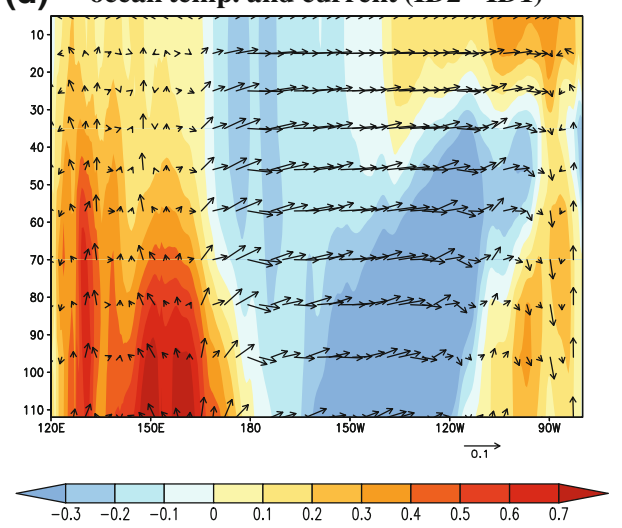

$5^{\circ} \mathrm{S}-5^{\circ} \mathrm{N}$, and $\mathbf{d}$ longitude-vertical section of ocean temperature and current anomalies averaged over $5^{\circ} \mathrm{S}-5^{\circ} \mathrm{N}$. The unit of vertical velocity in $\mathbf{c}$ and $\mathbf{d}$ are $-10^{-4} \mathrm{hPa} \mathrm{s}^{-1}$ and $10^{-4} \mathrm{~ms}^{-1}$, respectively

the specific heat of water, and $H$ denotes the mixing layer depth. The mixed layer depth was defined as the depth at which the temperature is $0.6{ }^{\circ} \mathrm{C}$ lower than the sea surface temperature, following Wang and McPhaden (2000). Here, a positive heat flux indicates atmosphere-heatingocean. Because the CRS in 1996/1997 originates from the equator (Fig. 2), in this study we will primarily focus on the heat budget analysis over the equatorial regions, one over the EWP $\left(5^{\circ} \mathrm{S}-5^{\circ} \mathrm{N}, 130^{\circ}-150^{\circ} \mathrm{E}\right)$ and the other over the ECP $\left(5^{\circ} \mathrm{S}-5^{\circ} \mathrm{N}, 155^{\circ} \mathrm{E}-175^{\circ} \mathrm{W}\right)$. A variable mixed layer depth is used in the heat budget as $H$ in ECP is much deeper $(\sim 100 \mathrm{~m})$ than that in EWP $(\sim 50 \mathrm{~m})$. This implies that given same amplitude of surface heat flux anomaly, the heating (cooling) rate in the EWP is about twice as large as that in the ECP. Previous studies (e.g., Rong et al. 2011) showed that high frequency motion may have an upscale feedback to lower frequency variability. To include the nonlinear rectification effect of interannual modes, monthly circulation and temperature data are first used to calculate the heat budget and then each term is 
Fig. 6 Same as in Fig. 1a, b except for the $850 \mathrm{hPa}$ stream function field (a)

EOF1/annual-mean
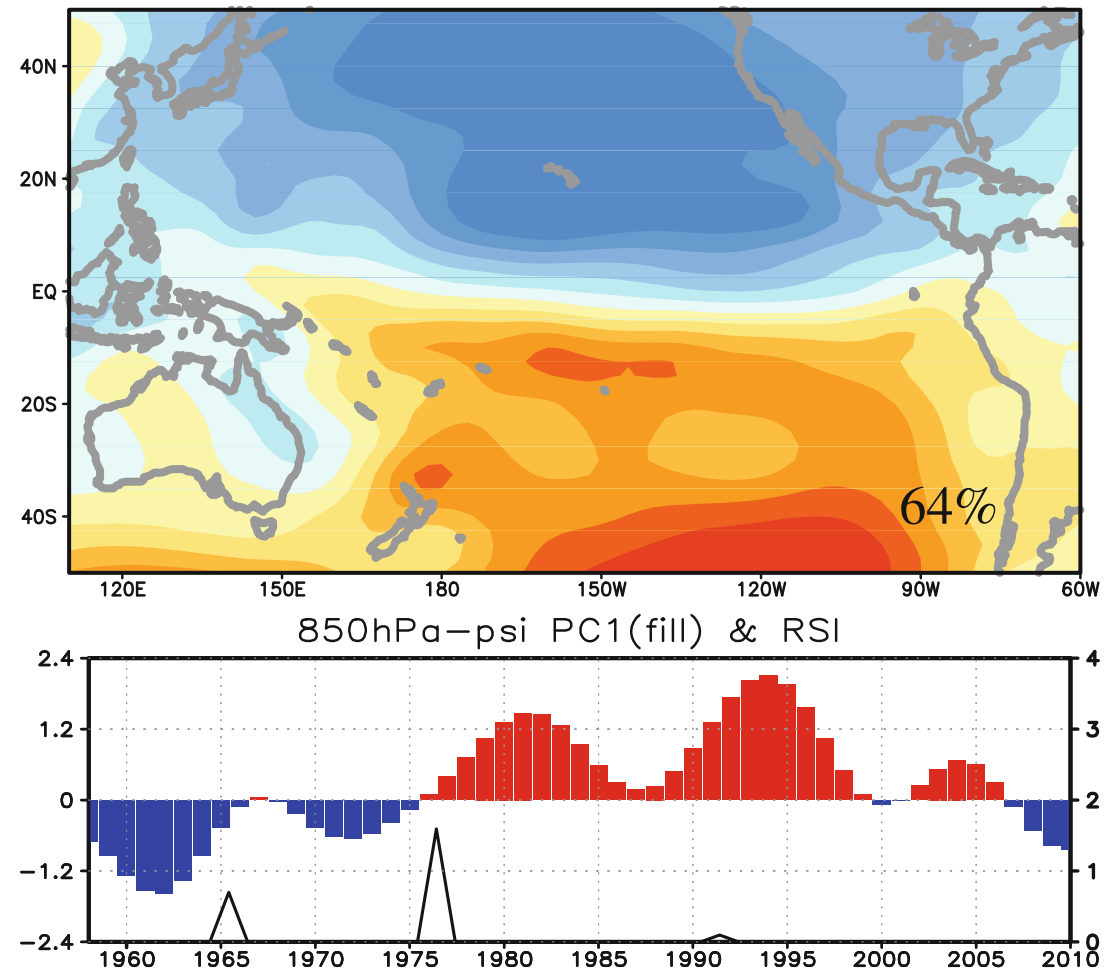

(b)

EOF2 /annual-mean
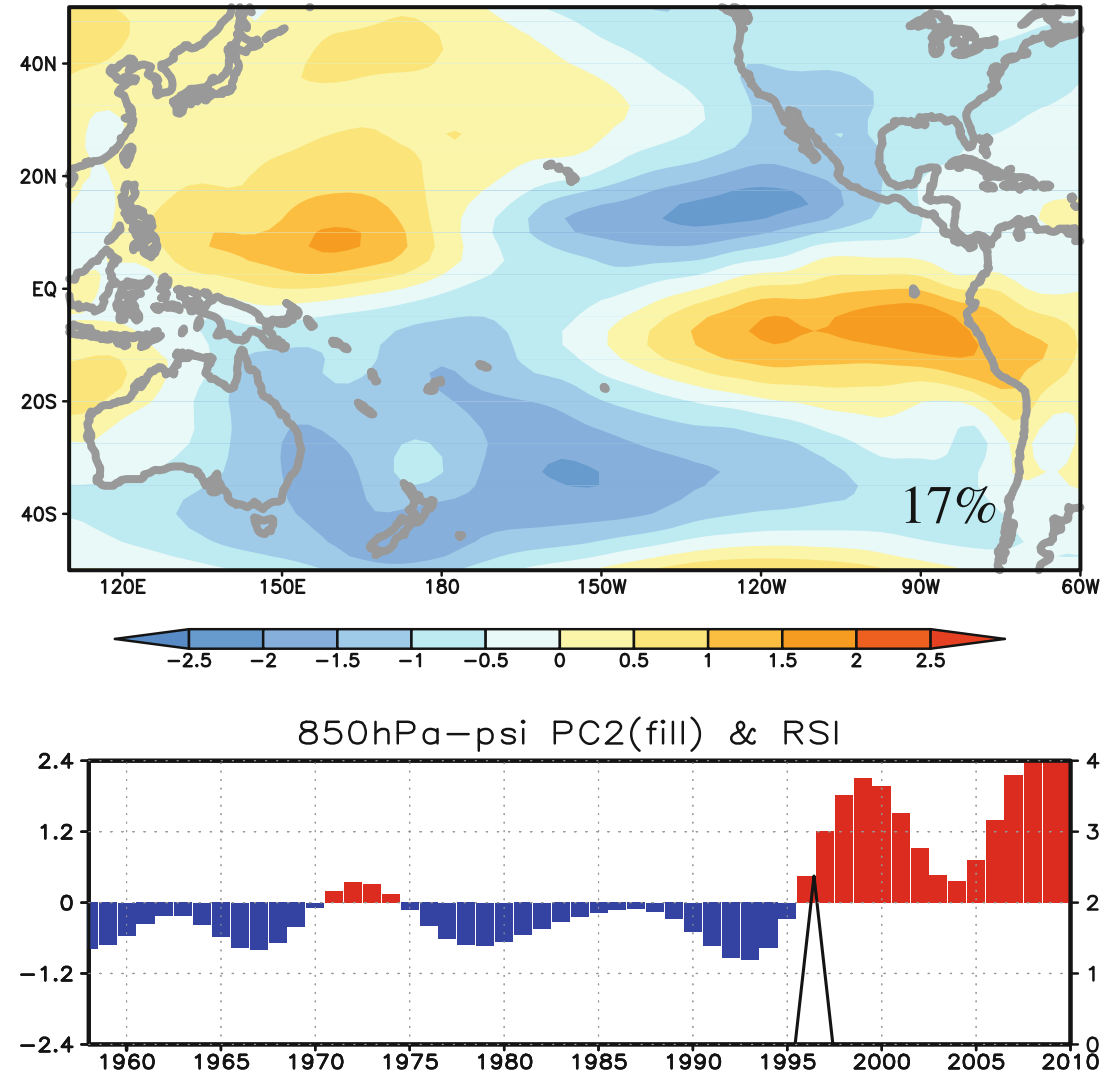

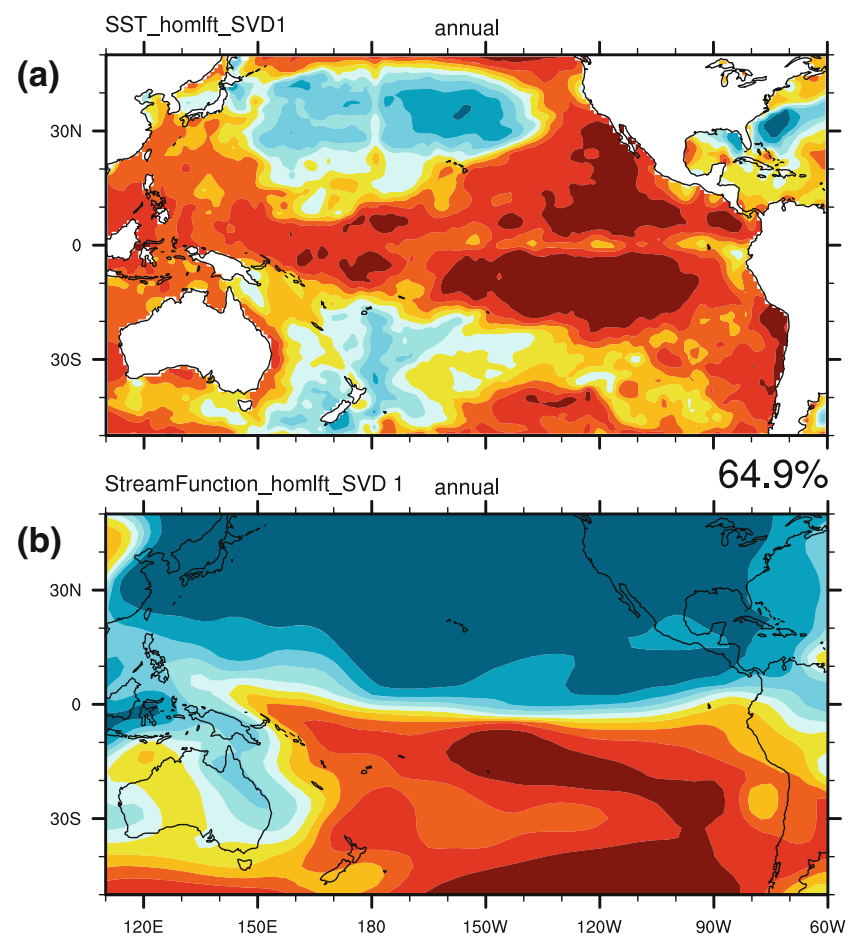

(c)

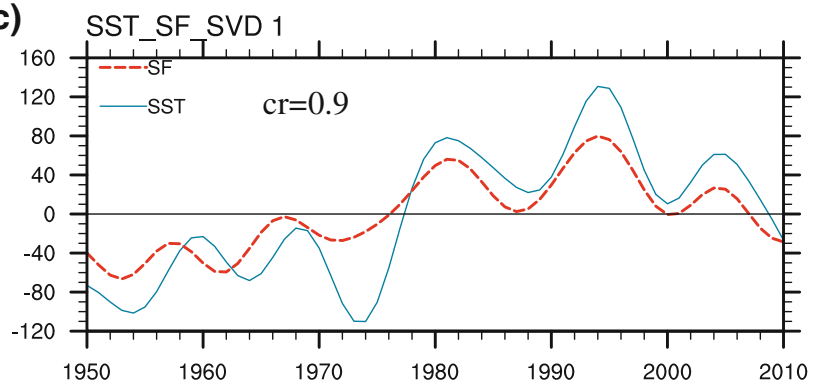

Fig. 7 (Left) Heterogenous correlation map for the leading SVD mode of a SST correlating against on the time series of the $850-\mathrm{hPa}$ stream function, b $850 \mathrm{hPa}$ stream function fields correlating against on the time series of the SST, and $\mathbf{c}$ the corresponding principle components. (Right) Same as in the left panels except for the second

further projected into the decadal timescale through an 8 -year low-pass filter.

The Hovmüller diagrams (averaged over $5^{\circ} \mathrm{S}-5^{\circ} \mathrm{N}$ ) of the mixed layer temperature shows that the temperature in the EWP transitions from a negative anomaly to a positive one in late 1995, whereas the transition from a positive anomaly to a negative one in the ECP is a few months late (Fig. 8a). This points out that the transition in the EWP slightly leads that in the ECP. Figure $8 \mathrm{a}$ also shows that the maximum temperature tendency associated with this transition occurred during the period of 1994-1997. Regarding this period as the SST transition period, next we intend to address what causes the warming and cooling tendencies in the western and central Pacific during the transition period.
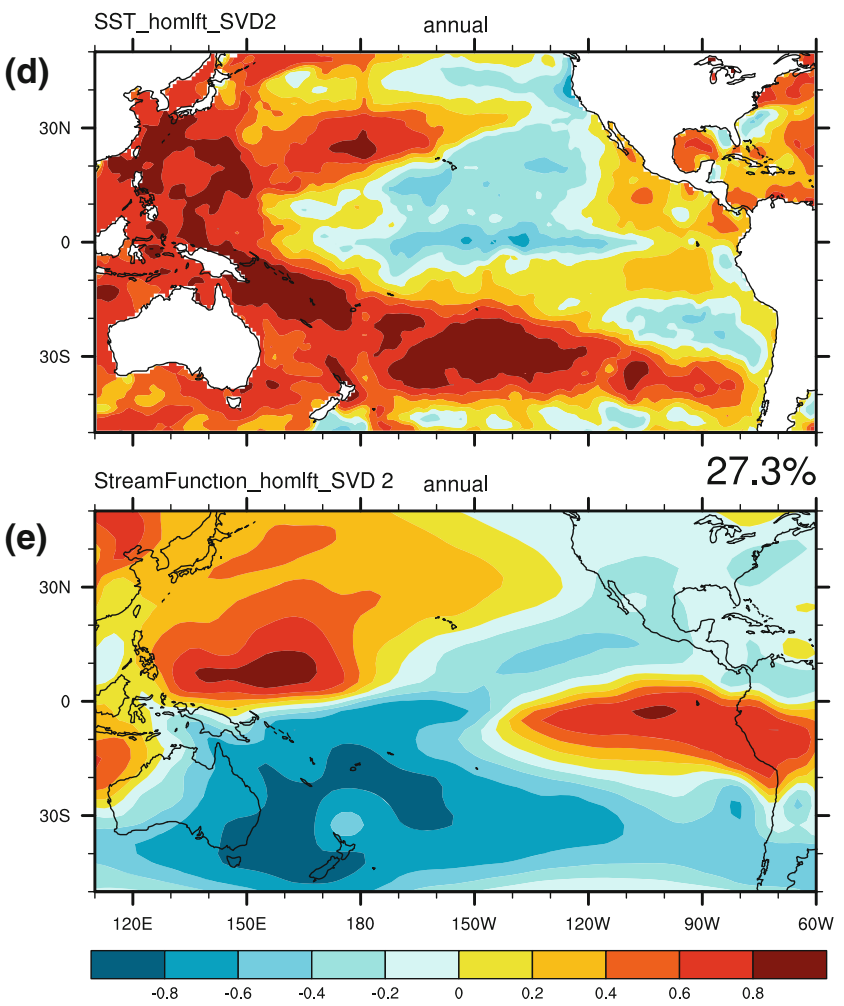

(f)

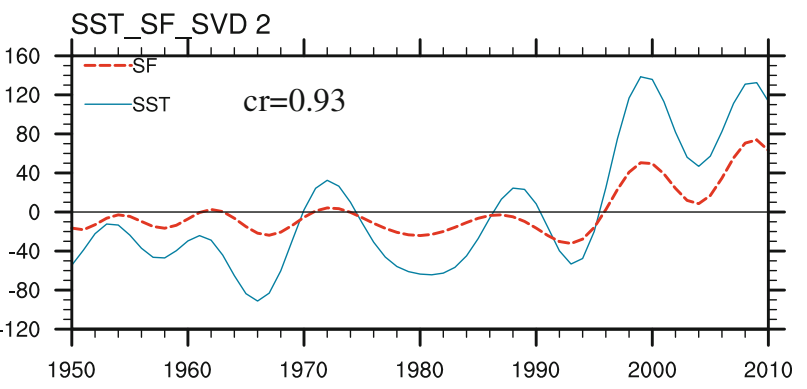

SVD mode. The fraction of the cross-covariance explained by the first(second) SVD mode is $64 \%(27 \%)$, and the correlation between the time series of the SST and $850 \mathrm{hPa}$ stream function part of the leading(second) SVD mode is 0.9 (0.93)

Figure 9 shows the mixed layer heat budget analysis result during the transition period. It is interesting to note that processes that cause the temperature change in the ECP and EWP are different. The EWP warming is primarily attributed to the surface heat flux forcing, whereas the ECP cooling is primarily caused by the ocean advection.

To investigate the cause of such a difference, we examine the time-longitude section of low-pass filtered precipitation, surface shortwave radiation, latent heat flux, sea surface height ( $\mathrm{SSH}$ ) and ocean advection fields along the equator (Fig. 8). It shows that prior to the transition period, a positive (negative) SSTA center appeared in the ECP (EWP). Associated with this positive zonal SST 
Fig. 8 a Hovmüller diagrams (averaged over $5^{\circ} \mathrm{S}-5^{\circ} \mathrm{N}$ ) of 8 -year low-pass filtered mixed layer temperature tendency (shading) and mixed layer temperature (contour). b-f same as in a but for the low-passfiltered $\mathbf{b}$ rainfall, $\mathbf{c}$ surface downward shortwave radiation, d surface latent heat flux and wind vector at $10 \mathrm{~m}$, e sea surface height and zonal wind stress (shading), and f temperature advection anomalies. The horizontal line denotes the timing of the CRS at the equator (a) T-Tend

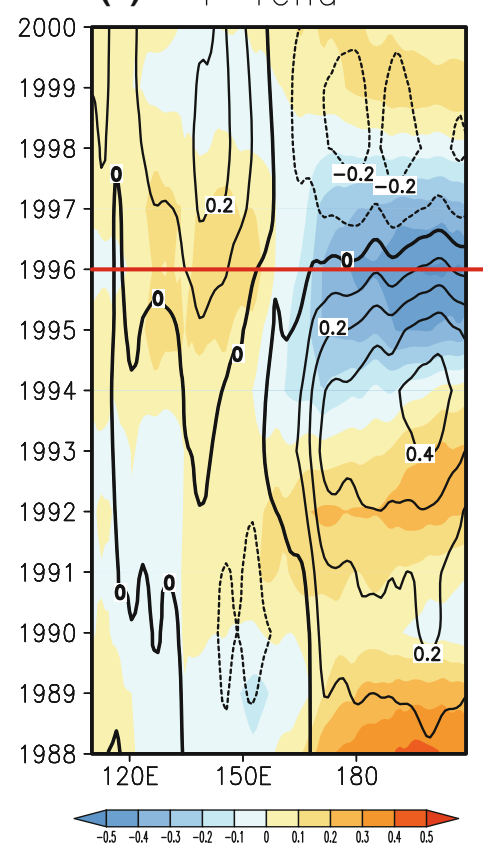

(b)

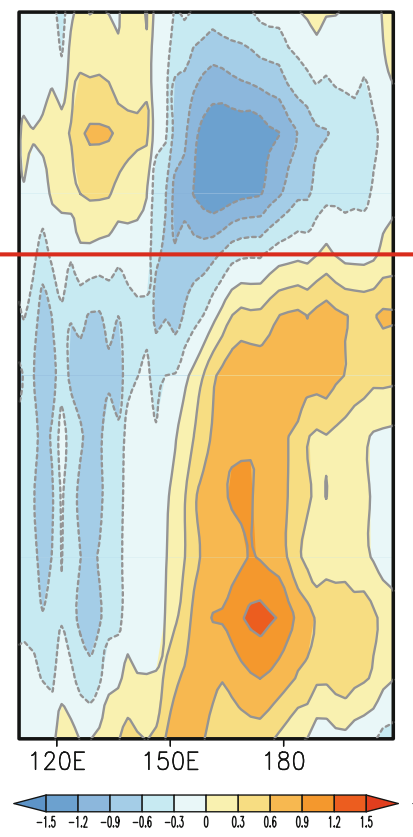

(c) SW $[5 s-5 n]$
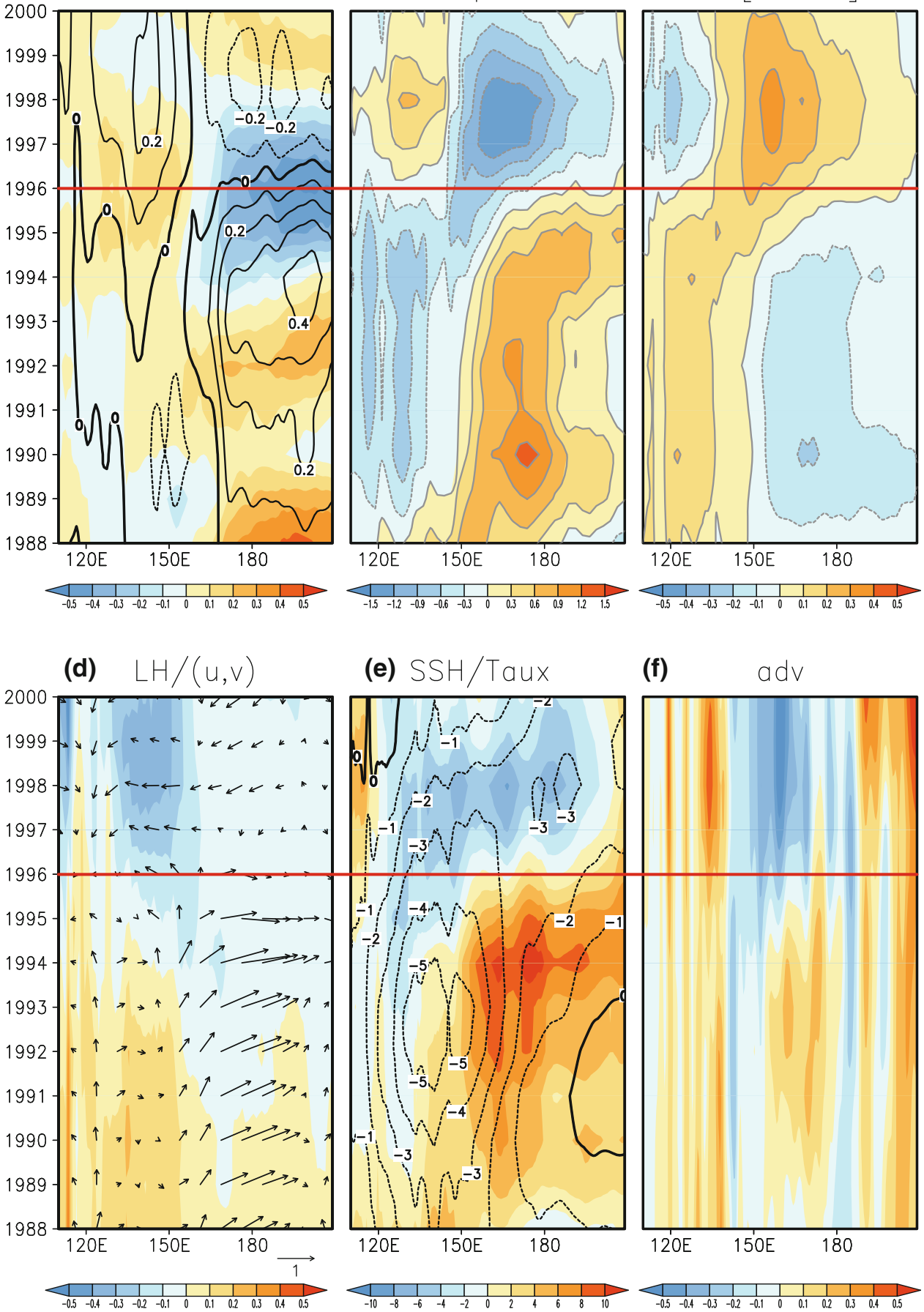

gradient were enhanced (suppressed) precipitation in the central (western) Pacific and strong westerly anomalies at the equator. As a consequence of this weakened Walker circulation, net surface shortwave radiation (SWR) tended to warm the SST in the EWP. This SWR anomaly creates an average heating rate of $5 \mathrm{Wm}^{-2}$ over the WP during 1994-1997, which is equivalent to a warming rate of $0.1 \mathrm{Kyr}^{-1}$ for the mixed layer temperature. Therefore, it appears that the warming in the EWP was initiated by the
SWR. In addition to the SWR, the surface latent heat flux (LH) also contributed partially to the initiation of the warming in the WP (Fig. 8d).

The initiation of the negative SSTA in the ECP is different from that in the EWP (Fig. 9b). Figure 8a shows that the termination of the SST in the ECP is about 6 months later than that in the EWP. Since the zonal-vertical overturning circulation reverses once the SSTA in the EWP changes from a negative to a positive value, a negative 

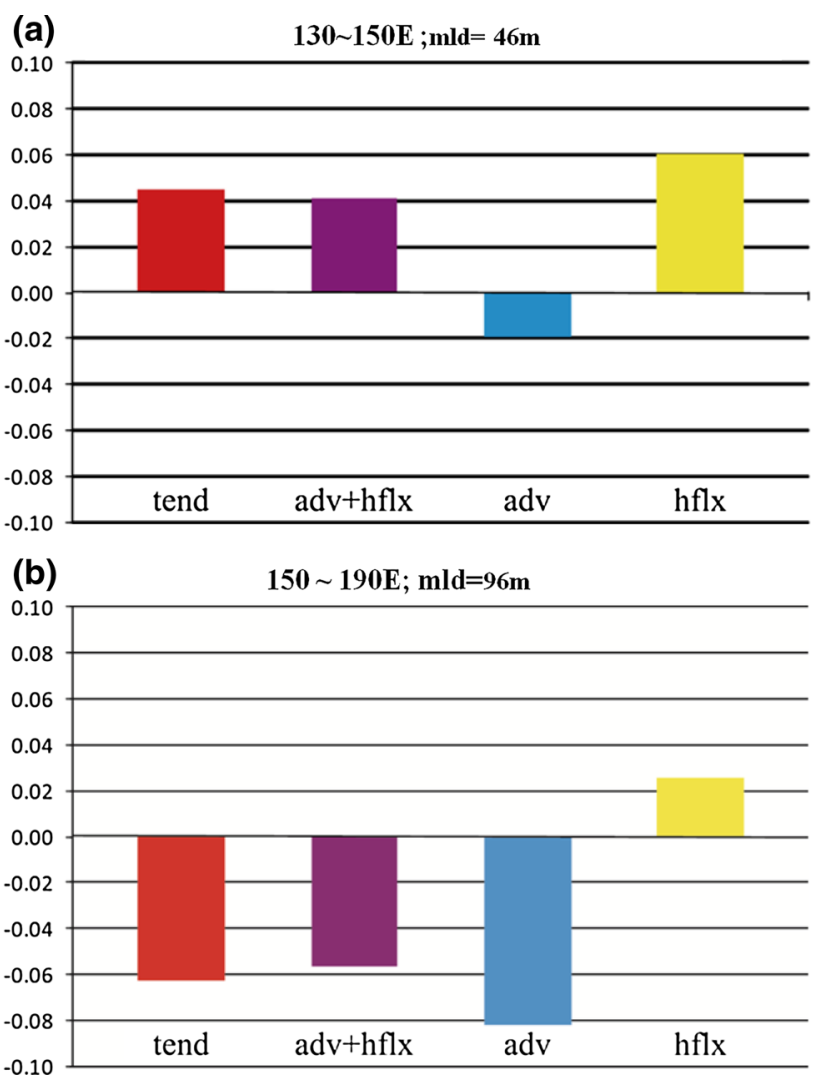

Fig. 9 The mixed layer heat budget terms during the transition period (1994-1997) over a the EWP $\left(5^{\circ} \mathrm{S}-5^{\circ} \mathrm{N}, 130^{\circ}-150^{\circ} \mathrm{E}\right.$, mixed layer depth: $46 \mathrm{~m})$ and $\mathbf{b}$ the ECP $\left(5^{\circ} \mathrm{S}-5^{\circ} \mathrm{N}, 155^{\circ} \mathrm{E}-175^{\circ} \mathrm{W}\right.$, mixed layer depth: $96 \mathrm{~m})$. Left to right observed mixed layer temperature tendency (unit: $\mathrm{Kyr}^{-1}$ ), estimated mixed layer temperature tendency (i.e., summation of oceanic advection and surface heat flux terms), the oceanic temperature advection term, and the surface heat flux term. All the terms had been multiplied by 2 for visualization

zonal wind stress anomaly appeared in the ECP after 1996 (Fig. 8e). The westward wind stress anomaly shoaled the SSH and generates an upwelling anomaly over the ECP. The upwelling and westward current anomalies produced a significant cold temperature advection, which cooled the SST in the ECP (Fig. 8f). A further decomposition of the 3D ocean temperature advection reveals that cold advection is dominated primarily by the vertical oceanic temperature advections. A further calculation reveals that the nonlinear temperature advection $\left(-w^{\prime} \cdot \partial T^{\prime} / \partial z\right)$ contributed approximately $50 \%$ of the total vertical temperature advection, whereas the advection of anomaly temperature by mean vertical motion $\left(-\bar{w} \cdot \partial T^{\prime} / \partial z\right)$ contributes about $30 \%$ and the anomalous advection of mean temperature $\left(-w^{\prime} \cdot \partial \bar{T} / \partial z\right)$ contributes about $20 \%$ (not shown). Since the prevailing trade wind was enhanced due to the easterly anomaly (Fig. 8d), the LH was enhanced. This cooling effect in the CP was partially offset by the local SWR anomaly. As a result, the oceanic zonal and vertical temperature advection processes dominate the SST change in the $\mathrm{CP}$ during the transition period.

\section{Conclusion and discussion}

A new climate regime shift in 1996/1997 was identified in the basin-wide SST field over the Pacific. The temporal and spatial characteristics and the physical processes associated with this CRS were investigated by diagnosing the observational data. The main results were illustrated in Fig. 10 and summarized as the following:

An abrupt warming in the equatorial WP and mid-latitude North and South Pacific and a cooling in the equatorial CP occurred in 1996/1997. This abrupt SST change was associated with the occurrence of a pair of low-level anticyclonic (cyclonic) gyres in the WP (CP) and a zonalvertical overturning circulation anomaly in the equatorial Pacific.

The impact of the long-term linear warming trend on the CRS in 1996/1997 is insignificant. Both the EOF and SVD analyses reveal that the CRS signal is robust and statistically significant.

The temporal evolution of the SSTA associated with the CRS shows that the decadal SST transition starts from the equatorial regions, and then extended to the extratropics and mid-latitude regions. In the tropics, a warming was firstly initiated in the EWP, and it was followed by a cooling in the ECP.

A mixed layer heat budget analysis suggests that the physical processes that trigger the CRS differ in the EWP and ECP. Prior to the transition period, a persistent positive SSTA center appeared in the ECP. In response to this warm SSTA forcing, there were enhanced (suppressed) precipitation in the central (western) Pacific and strong westerly anomalies at the equator. As a consequence of this weakened Walker circulation, net surface shortwave radiation (SWR) tended to warm the SST in the EWP. This SWR anomaly creates an average heating rate of $5 \mathrm{Wm}^{-2}$ over the WP during 1994-1997. The triggering of cooling in the ECP was about 6 months later than that in the EWP and was primarily attributed to anomalous oceanic zonal and vertical temperature advections.

Previous studies (e.g., Yang et al. 2007) suggested that the warming in the IO basin may have a remote impact on the SST change in the Pacific. However, our analysis indicates that a negative precipitation anomaly is in phase with a warm SSTA in the central equatorial IO, suggesting that the local SSTA is a passive response to the SWR forcing. Thus the IO warm SSTA alone cannot induce an easterly wind anomaly in the equatorial Pacific, to trigger a climate regime shift in the Pacific. Our analysis suggests that the CRS in 1996/1997 may arise from internal air-sea 
Fig. 10 Schematic diagrams illustrating key processes that are responsible for the initiation and maintenance of the CRS in the equatorial Pacific in 1996/1997

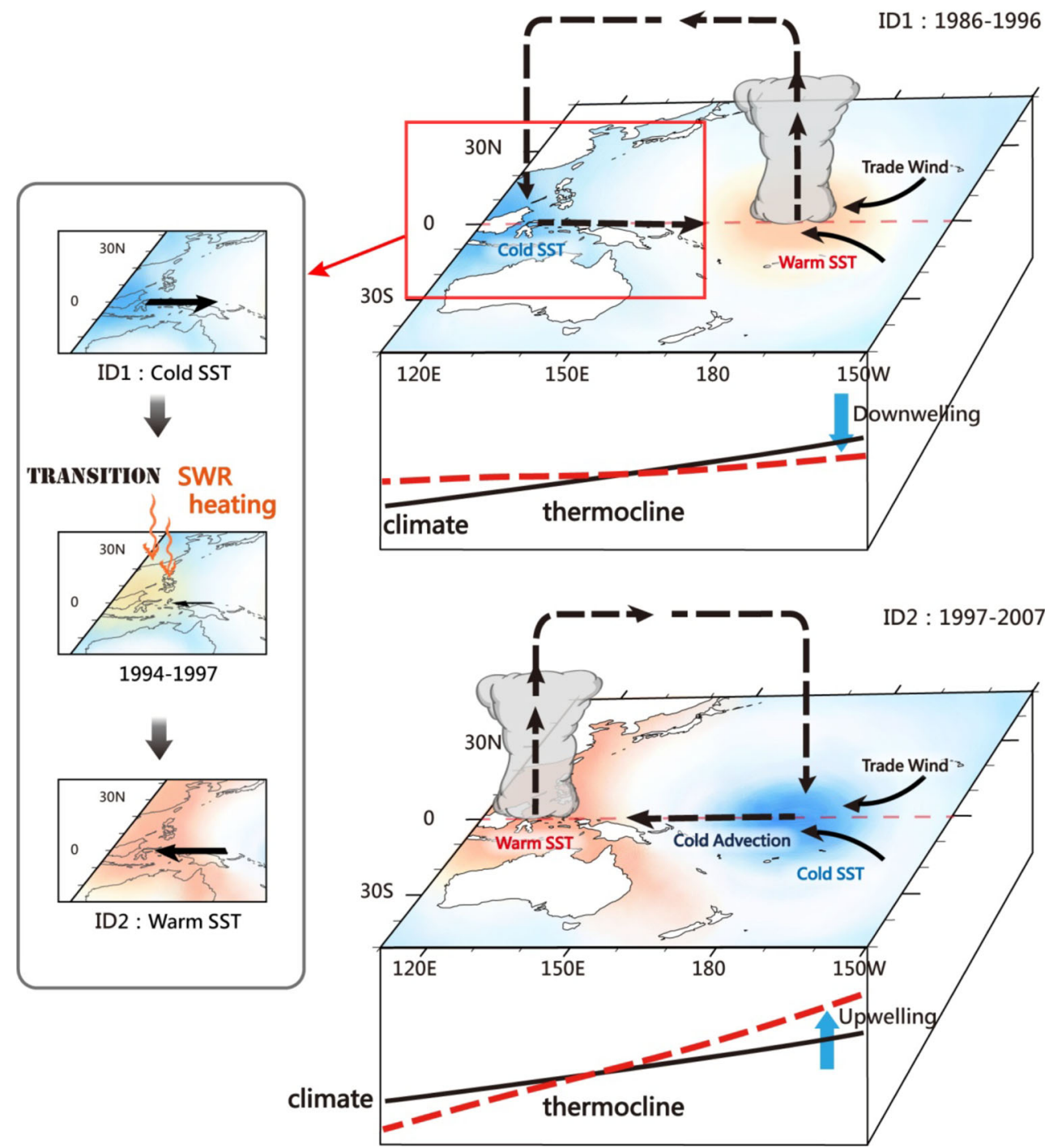

coupled dynamics within the Pacific. There is little evidence to claim that the CRS is caused by the global warming trend.

The timing of CRS may differ when different data sources or different analysis methods are used. The regime shift in 1998/1999 pointed by previous studies such as McPhaden et al. (2011) was based on the behavior change of central Pacific (CP) El Niño, whereas in the current study, a climate regime shift was detected based on basinscale SST field. Besides, in the current study a regime shift index (Rodionov 2004) was used to detect specific timing of CRS and whether or not the CRS is statistically significant. Although the timing of the current CRS is slightly different from that of McPhaden et al. (2011), the so derived mean-state change in the equatorial Pacific is quite similar, i.e., a La Nina-like SST pattern occurred in the equatorial Pacific Ocean after late 1990s. From the equatorial SST feature, one may regard the two CRSs in
$1996 / 97$ and $1998 / 99$ as the shift of the same physical mode.

Previous studies (e.g., Sun and Yu 2009; Su et al. 2010) showed that the shoaling of the mean (background) thermocline depth in the equatorial eastern Pacific enhances the thermocline-SST feedback, which is favorable for the developing of extreme ENSO event. As shown in Fig. 9, a La Nina-like mean state change occurs after the CRS in $1996 / 1997$, i.e., the thermocline depth in the equatorial central-eastern (western) Pacific shoals (deepens) after the CRS in 1996/1997. Therefore the mean state change associated the CRS in 1996/1997 creates a large-scale environment favorable for the developing of the extreme El Niño event in 1997/1998. This possible connection between the 1996/1997 CRS and the 1997/1998 ENSO is deserved our further exploring. Besides, several studies have demonstrated the significant impact of the regime shift in 1976/1977 on global and regional climate, such as 
the TC activity in the WNP (e.g., Chia and Ropelewski 2002). It should be interesting to conduct a parallel study to examine the climate impact of this new regime shift in 1996/1997.

Acknowledgments Comments of two anonymous reviewers are highly appreciated. This study was supported by NSC 99-2628-M133001 and NSC100-2111-M133-001. TL acknowledges support by ONR Grant N000141210450 and by the International Pacific Research Center that is sponsored by the Japan Agency for MarineEarth Science and Technology (JAMSTEC). This is SOEST contribution number 8960 and IPRC contribution number 991 .

Open Access This article is distributed under the terms of the Creative Commons Attribution License which permits any use, distribution, and reproduction in any medium, provided the original author(s) and the source are credited.

\section{References}

Ashok K, Behera S, Rao AS, Weng H, Yamagata T (2007) El Niño Modoki and its possible teleconnection. J Geophys Res 112:C11007. doi:10.1029/2006JC003798

Bond NA, Overland JE, Spillane M, Stabeno P (2003) Recent shifts in the state of the North Pacific. Geophys Res Lett 30:2183. doi: 10.1029/2003GL018597

Bretherton CS, Smith C, Wallace JM (1992) An intercomparison of methods for finding coupled patterns in climate data. J Clim 5:541-560

Carton JA, Giese BS, Grodsky SA (2005) Sea level rise and the warming of the oceans in the SODA ocean reanalysis. J Geophys Res 110. doi: $10.1029 / 2004 J C 002817$

Chang C-P, Li T (2000) A theory of the tropical tropospheric biennial oscillation. J Atmos Sci 57:2209-2224

Chang C-P, Zhang YS, Li T (2000a) Interannual and interdecadal variations of the East Asian summer monsoon and tropical Pacific SSTs: Part I: Role of subtropic ridges. J Clim 13:4310-4325

Chang C-P, Zhang YS, Li T (2000b) Interannual and interdecadal variations of the East Asian summer monsoon and tropical Pacific SSTs: part II: meridional structure of the monsoon. J Clim 13:4326-4340

Chia HH, Ropelewski CF (2002) The interannual variability in the genesis location of tropical cyclones in the northwest Pacific. J Clim 15:2934-2944

Chung P-H, Li T (2013) Interdecadal relationship between the mean state and El Niño types. J Clim 26:361-379. doi:10.1175/ JCLID-12-00106.1

Gill AE (1980) Some simple solutions for heat-induced tropical circulation. Q J R Meteorol Soc 106:447-462

Hung C-W, Hsu H-H, Lu M-M (2004) Decadal oscillation of spring rain in northern Taiwan. Geophys Res Lett 31:L22206. doi: 10.1029/2004GL021344

Kalnay E et al (1996) The NCEP/NCAR 40-year reanalysis project. Bull Am Meteorol Soc 77:437-471

Kwon MH, Jhun J-G, Wang B, An S-I, Kug J-S (2005) Decadal change in relationship between east Asian and WNP summer monsoons. Geophys Res Lett 32:L16709

Li T, Zhang Y, Lu E, Wang D (2002) Relative role of dynamic and thermodynamic processes in the development of the Indian Ocean dipole: An OGCM diagnosis. Geophys Res Lett 29:2110. doi:10.1029/2002GL015789
Li T, Liu P, Fu X, Wang B, Meehl G (2006) Spatiotemporal structures and mechanisms of the tropospheric biennial oscillation in the Indo-Pacific warm ocean regions. J Clim 19:3070-3087

Li C, Li T, Liang J, Gu D, Lin A, Zheng B (2010) Interdecadal variations of meridional winds in the South China Sea and their relationship with summer climate in China. J Clim 23:825-841

Liebmann B, Smith CA (1996) Description of a complete (Interpolated) outgoing longwave radiation dataset. Bull Am Meteorol Soc 77:1275-1277

Matsuno T (1966) Quasi-geostrophic motions in the equatorial area. J Meteorol Soc Jpn 44:25-43

McPhaden MJ, Lee T, McClurg D (2011) El Niño and its relationship to changing background conditions in the tropical Pacific. Geophys Res Lett 38:L15709. doi:10.1029/2011GL048275

Meehl GA (1993) A coupled air-sea biennial mechanism in the tropical Indian and Pacific regions: role of the ocean. J Clim $6: 31-41$

Meehl GA, Arblaster JM, Jr WGS (1998) Glbal scale decadal climate variability. Geophys Res Lett 25:3983-3986

Miller AJ, Cayan DR, Barnett TP, Graham NE, Oberhuber JM (1994) The 1976-77 climate shift of the Pacific Ocean. Oceanography 7:21-26

North G, Bell T, Cahalan R, Moeng F (1982) Sampling errors in the estimation of empirical orthogonal functions. Mon Weather Rev 110:699-706

Peterson WT, Schwing FB (2003) A new climate regime in northeast Pacific ecosystems. Geophys Res Lett 30. doi:10.1029/2003 GL017528

Rayner NA, Parker DE, Horton EB, Folland CK, Alexander LV, Rowell DP, Kent EC, Kaplan A (2003) Global analyses of sea surface temperature, sea ice, and night marine air temperature since the late nineteenth century. J Geophys Res 108:4407. doi: 10.1029/2002JD002670

Rodionov SN (2004) A sequential algorithm for testing climate regime shifts. Geophys Res Lett 31:L09204. doi:10.1029/2004 GL019448

Rong X, Zhang R, Li T, Su J (2011) Upscale feedback of highfrequency winds to ENSO. Q J R Meteorol Soc 137:894-907

Smith TM, Reynolds RW, Peterson TC, Lawrimore J (2008) Improvements to NOAA's historical merged land-ocean surface temperature analysis (1880-2006). J Clim 21:2283-2296

Su J, Zhang R, Li T, Rong X, Kug J-S, Hong C-C (2010) Causes of the El Niño and La Niña amplitude asymmetry in the equatorial eastern Pacific. J Clim 23:605-617

Sun F, Yu J-Y (2009) A 10-15-yr modulation cycle of ENSO intensity. J Clim 22:1718-1735

Thiébaux HJ, Zwiers FW (1984) The interpretation and estimation of effective sample size. J Clim Appl Meteor 23:800-811

Ting M, Kushnir Y, Seager R, Li C (2009) Forced and internal twentieth-century SST trends in the North Atlantic. J Clim 22:1469-1480

Wang B (1995) Interdecadal changes in El Niño onset in the last four decades. J Clim 8:258-267

Wang W, McPhaden MJ (2000) The surface-layer heat balance in the equatorial Pacific Ocean. Part II: interannual variability. J Phys Oceanogr 30:2989-3008

Wang B, Wu R, Fu X (2000) Pacific-East Asian teleconnection: how does ENSO affect Asian climate? J Clim 13:1517-1536

Wu B, Zhou T, Li T (2009) Contrast of rainfall-SST relationships in the western North Pacific between the ENSO developing and decaying summers. J Clim 22:4398-4405

Wu B, Li T, Zhou T (2010) Relative contributions of the Indian Ocean and local SST anomalies to the maintenance of the Western North Pacific anomalous anticyclone during the El Niño decaying summer. J Clim 23:2974-2986 
Xiang B, Wang B, Li T (2012) A new paradigm for the predominance of standing Central Pacific Warming after the late 1990s. Clim Dyn 39:1-14

Yang JL, Liu QY, Xie S-P, Liu Z-Y, Wu L-I (2007) Impact of the Indian Ocean SST basin mode on the Asian summer monsoon. Geophys Res Lett 34:L02708

Yu L, Jin X, Weller RA (2008) Multidecade global flux datasets from the objectively analyzed air-sea fluxes (OAFlux) project: latent and sensible heat fluxes, ocean evaporation, and related surface meteorological variables. Woods Hole Oceanographic
Institution, OAFlux project technical report. OA-2008-01, 64 pp. Woods Hole, MA

Zhang Y, Li T, Wang B (2004) Decadal change of snow depth over the Tibetan Plateau in spring: the associated circulation and its relationship to the East Asian summer monsoon rainfal. J Clim 17:2780-2793

Zhou T, Yu R, Zhang J, Drange H, Cassou C, Deser C, Hodson DLR, Sanchez-Gomez E, Li J, Keenlyside N, Xin X, Okumura Y (2009) Why the western Pacific subtropical high has extended westward since the late 1970s. J Clim 22:2199-2215 